\title{
Transient Complete Heart Block Following Femoral Arterial Sheath Removal: An Extreme Case of Vasovagal Reflex Syndrome
}

\author{
Ashwin Kodliwadmath ${ }^{1} \oplus$, Rohit Walia ${ }^{\circledR} \odot$, Ramlal Ola ${ }^{3} \odot$, Pintu Sharma ${ }^{4} \odot$ \\ Indian Journal of Critical Care Medicine (2021): 10.5005/jp-journals-10071-23888
}

\section{Dear Sir,}

We report the case of a 65-year-old gentleman, nonhypertensive, nondiabetic, chronic smoker who presented to us with typical anginal discomfort for the past 2 weeks. Baseline 12-lead surface electrocardiogram (ECG) showed sinus rhythm with ST depression in V4 to V6; echocardiography showed no regional wall motion abnormality with a left ventricular ejection fraction of $60 \%$; and troponin I was $0.02 \mu \mathrm{g} / \mathrm{L}$ (normal $<0.12 \mu \mathrm{g} / \mathrm{L}$ ). He was diagnosed as suffering from acute coronary syndrome-unstable angina-and started on medical management including dual antiplatelets, statins, anticoagulants, and antianginals. Because of the feeble radial pulses, he was taken up for coronary angiography from the right femoral route, which showed a right dominant circulation and a mid-left anterior descending (LAD) coronary artery having discrete $90 \%$ stenosis, while the other coronary arteries were normal. The patient underwent successful percutaneous coronary intervention $(\mathrm{PCl})$ to mid-LAD using one sirolimus-eluting stent of size $3 \times 16 \mathrm{~mm}$. He was shifted to the coronary care unit for post- $\mathrm{PCl}$ management. After 6 hours of the $\mathrm{PCl}$ and when the activated clotting time was 120 seconds, the femoral arterial sheath was removed under all aseptic precautions by the manual compression method under adequate local anesthesia- $10 \mathrm{~mL}$ of $1 \%$ lignocaine. Three minutes after sheath removal, the patient reported increasing uneasiness, nausea, yawning, and anxiety. His heart rate decreased from 86 beats per minute (bpm) to $49 \mathrm{bpm}$, blood pressure (BP) fell from 136/74 to $84 / 39 \mathrm{~mm} \mathrm{Hg}$, and the bedside monitor showed atrioventricular dissociation with complete heart block $(\mathrm{CHB})$ with a ventricular rate of around $49 \mathrm{bpm}$, and narrow QRS complexes with junctional escape rhythm suggestive of intranodal block (Fig. 1). No femoral or jugular venous access was available for emergency temporary pacemaker insertion. In view of the clinical scenario suggestive of vasovagal reflex syndrome (VVRS), he was rushed with $500 \mathrm{~mL}$ of intravenous normal saline $(0.9 \% \mathrm{NaCl})$ and $0.6 \mathrm{mg}$ of atropine injection. Immediately after atropine injection, his heart rate improved to $110 \mathrm{bpm}$ and BP improved to $110 / 72 \mathrm{~mm} \mathrm{Hg}$ and the $\mathrm{CHB}$ reverted to sinus rhythm, even before it could be documented on a 12-lead ECG. ECG taken after achieving hemostasis showed sinus tachycardia and ST depression in V4 to V5 (Fig. 2). The rest course of the hospital stay was uneventful, and the patient was discharged with stable vitals on guideline-directed medical therapy.

VVRS is a common complication following sheath removal, characterized by hypotension, sinus bradycardia, and rarely by sinus arrest. ${ }^{1,2}$ Clinical presentation includes light-headedness, yawning, nausea, vomiting, diaphoresis, anxiety, bradycardia, and hypotension. ${ }^{3}$ Though sinus arrest for 4 to 10 seconds is known after sheath removal, ${ }^{2}$ CHB following sheath removal has not

\begin{abstract}
${ }^{1-4}$ Department of Cardiology, All India Institute of Medical Sciences, Rishikesh, Uttarakhand, India

Corresponding author: Ashwin Kodliwadmath, Department of Cardiology, All India Institute of Medical Sciences, Rishikesh, Uttarakhand, India, Phone: +91 8312470157, +91 9743458960, e-mail: ashrocks33@gmail.com

How to cite this article: Kodliwadmath A, Walia R, Ola R, Sharma P. Transient Complete Heart Block Following Femoral Arterial Sheath Removal: An Extreme Case of Vasovagal Reflex Syndrome. Indian J Crit Care Med 2021;25(7):825-827.

Source of support: Nil

Conflict of interest: None
\end{abstract}

been described in the literature to the best of our knowledge. The treatment of VVRS includes intravenous fluids and atropine injection. ${ }^{4}$ Our case shows that VVRS in the extreme case can lead to $\mathrm{CHB}$ with narrow QRS and junctional escape rhythm at rates of 40-60 bpm indicating an intranodal block. ${ }^{5}$ Thus, along with monitoring of pulse and $\mathrm{BP}$, continuous cardiac rhythm monitoring during sheath removal is of utmost importance as atrioventricular conduction disturbances including $\mathrm{CHB}$ can rarely occur, with a quick response to atropine.

\section{Contributor Statement}

- Conception and design or analysis and interpretation of data, or both-Ashwin Kodliwadmath, Rohit Walia

- Drafting of the manuscript or revising it critically for important intellectual content-Ramlal Ola and Pintu Sharma

- Final approval of the manuscript submitted-Ashwin Kodliwadmath and Rohit Walia

- Agreement to be accountable for all aspects of the work in ensuring that questions related to the accuracy or integrity of any part of the work are appropriately investigated and resolved: Rohit Walia, Ashwin Kodliwadmath, Ramlal Ola, and Pintu Sharma

\section{OrCID}

Ashwin Kodliwadmath (1) https://orcid.org/0000-0002-1709-3579

Rohit Walia (1) https://orcid.org/0000-0001-9405-5990

Ramlal Ola $\odot$ https://orcid.org/0000-0001-8206-702X

Pintu Sharma (1) https://orcid.org/0000-0002-2048-7640

() Jaypee Brothers Medical Publishers. 2021 Open Access This article is distributed under the terms of the Creative Commons Attribution 4.0 International License (https://creativecommons.org/licenses/by-nc/4.0/), which permits unrestricted use, distribution, and non-commercial reproduction in any medium, provided you give appropriate credit to the original author(s) and the source, provide a link to the Creative Commons license, and indicate if changes were made. The Creative Commons Public Domain Dedication waiver (http://creativecommons.org/publicdomain/zero/1.0/) applies to the data made available in this article, unless otherwise stated. 


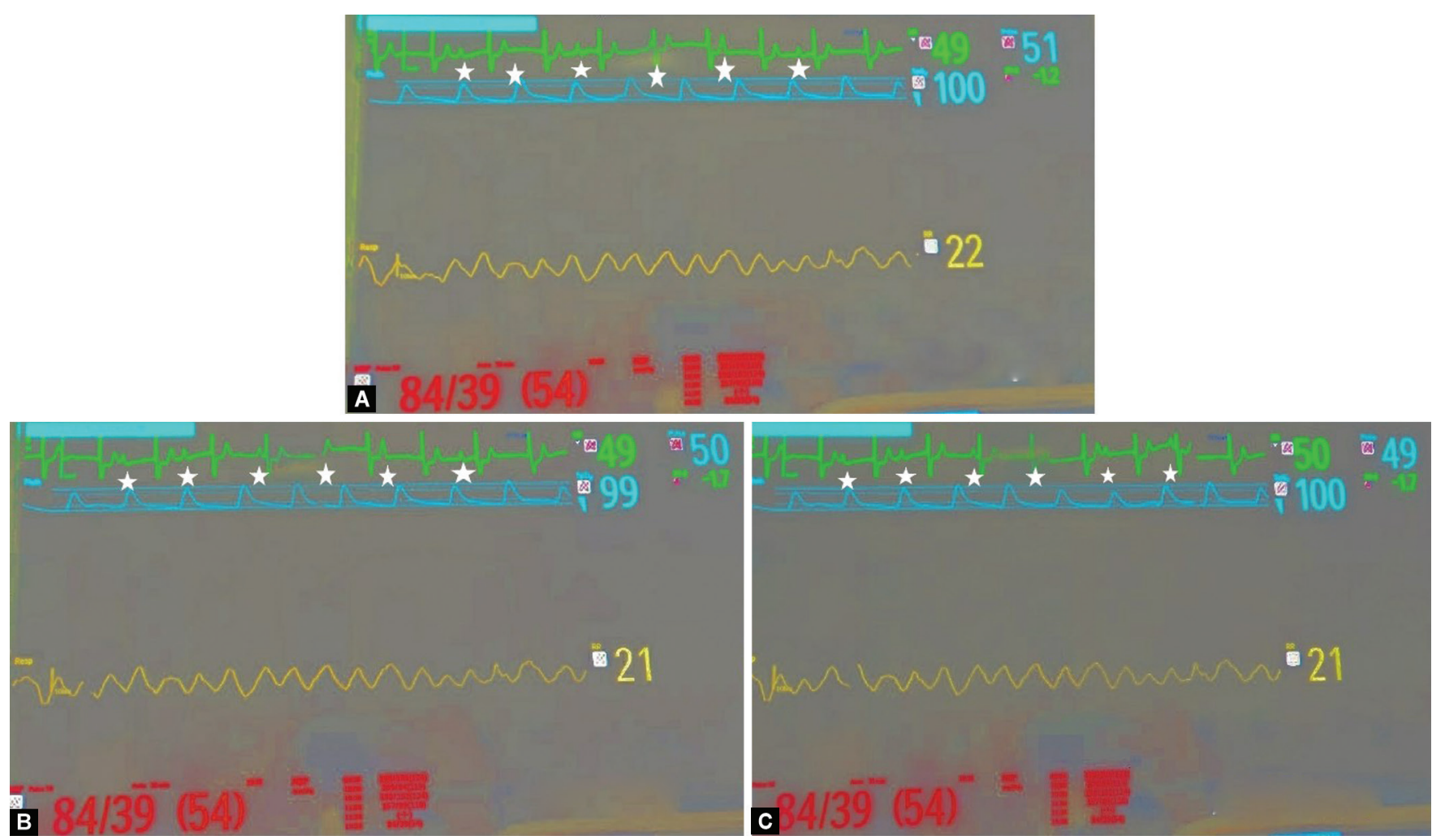

Figs $1 \mathrm{~A}$ to C: Series of bedside patient monitor images showing bradycardia with a heart rate of $49-50$ bpm, hypotension with a blood pressure of $84 / 39 \mathrm{~mm} \mathrm{Hg}$, normal oxygen saturation of $99-100 \%$; and lead I electrocardiogram strip showing regular P-P intervals, narrow QRS complexes with regular R-R intervals with atrioventricular dissociation suggestive of intranodal CHB (third-degree atrioventricular block) (*indicates the P waves)

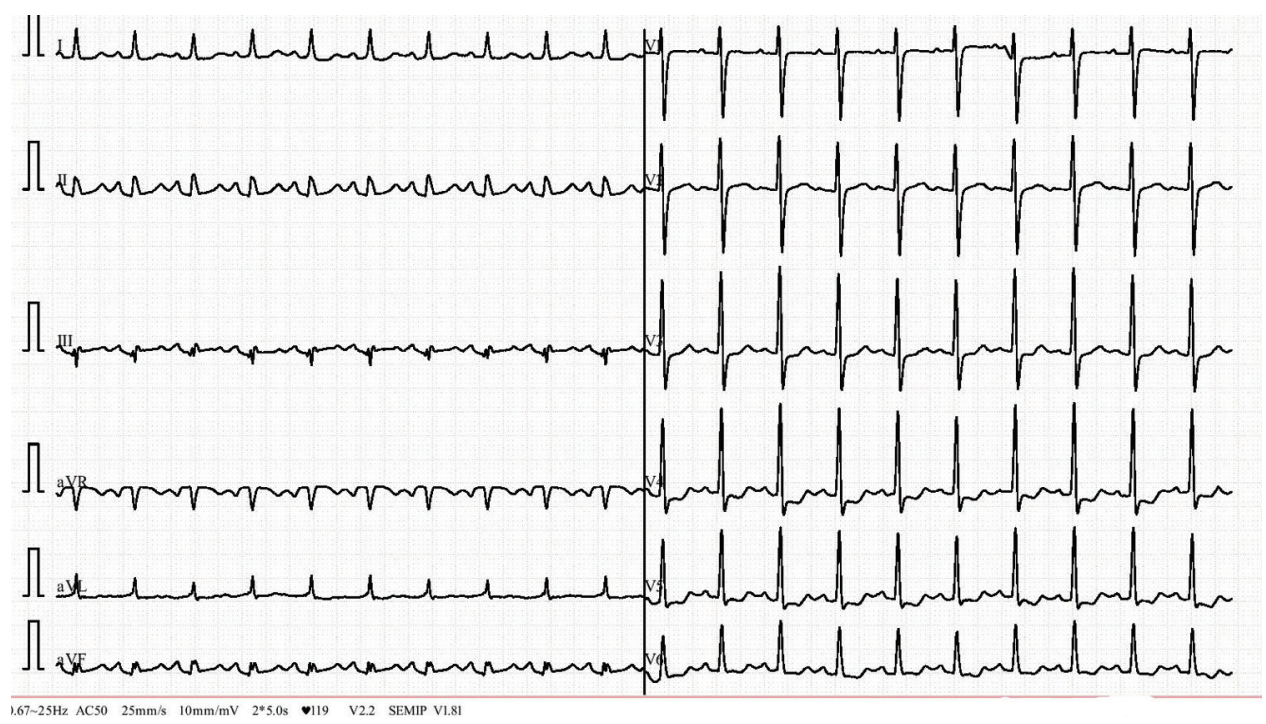

Fig. 2: Twelve-lead surface electrocardiogram done post-atropine, after hemostasis after sheath removal was achieved, showed sinus tachycardia with a heart rate of $125 \mathrm{bpm}$ and ST depressions in V4 to V5 


\section{References}

1. Kang $X Q, X u G$, Tian $H Y$, Jiang $B E$, Song $Y Z$. An analysis of the intervention effect of perioperative evidence-based nursing on orthopedic trauma patients' vagal reflex. Eur Rev Med Pharmacol Sci 2015;19(14):2537-2543.PMID: 26221879.

2. Herlevsen P, Andersen PT. Constitutional predisposition to vasovagal syncope: an additional risk factor in patients exposed to electrical injuries? Br Heart J 1987;57(3):284-285. DOI: 10.1136/hrt.57.3.284.

3. Rama BN, Mohiuddin SM, Mooss AN, Khemani AK, Ryschon $K L$, Lucas $B D$, et al. Double-blind, randomized, placebo- controlled evaluation of atropine to prevent vasovagal reaction during removal of femoral arterial sheaths. Pharmacotherapy 1997;17(5):867-873. https://doi.org/10.1002/j.1875-9114.1997. tb03776.x. PMID: 9324175.

4. Moscucci M. Complications. In: Moscucci M, editors. Grossman and Baim's cardiac catheterization, angiography and intervention. 8th ed. Philadelphia: Lippincott Williams and Wilkins; 2014. p. 92-93.

5. Vijayaraman $P$, Ellenbogen KA. Bradyarrhythmias. In: Fuster $V_{\text {, }}$ Harrington RA, Narula J, Eapen ZJ, editors. Hurst's the heart. 14th ed. United States of America: McGraw Hill Education; 2017. p. 2021. 